\title{
Enhancing Pre-Service Teachers' Noticing: A Learning Environment about Fraction Concept
}

\author{
Pedro Ivars \\ Departamento de Innovación y Formación Didáctica, University of Alicante, Alicante, Spain \\ Pere.ivars@ua.es
}

Received: January $26^{\text {th }}, 2021$

Revised: February $14^{\text {th }}, 2021$

Accepted: February $17^{\text {th }}, 2021$

\begin{abstract}
Professional noticing allows teachers to recognise important events in a classroom and give effective responses using their knowledge. Hence developing this competence in teacher training programs is an issue in the Mathematics Education field. In this study, we present the design of a learning environment about the part-whole meaning of fraction to develop pre-service primary school teachers' noticing of students' mathematical thinking. The learning environment is designed around three tasks (vignettes) that pre-service teachers have to analyse using knowledge from research on mathematics education provided as a students' hypothetical learning trajectory. Eighty-five pre-service primary school teachers participated in this learning environment. Pre-service teachers' written answers to the three tasks are the data of this study. Results allow us to characterise the enhancement of pre-service teacher noticing through looking at the changes in the discourse generated in the three tasks.
\end{abstract}

Keywords: fraction; hypothetical learning trajectory; pre-service teacher; representations of practice; teacher noticing.

\section{INTRODUCTION}

During a mathematics lesson, a teacher faces overlapping situations and interactions simultaneously, hindering their attention to all of them. In this context, teachers should focus their attention on those classroom situations or interactions that could potentially enrich students' mathematical learning (Mason, 2002; van Es, \& Sherin, 2002). In fact, NCTM (2014) points out that teaching effectively implies that teachers "elicit evidence of students' current mathematical understanding and use it as the basis for making instructional decisions" (p. 53). From this perspective, effective teaching implies observing students, listening attentively to their ideas and explanations, planning objectives and using the information to make instructional decisions.

Therefore, teachers must develop greater flexibility in recognising students' mathematical thinking while teaching (van Es, \& Sherin, 2002) and must be 
aware of what happens in their classrooms and how to manage it (Mason, 2002; 2020). In this context, teacher noticing has been conceptualised as a competence that allows teachers to recognise important events in a classroom and give effective responses (Mason, 2002). Hence, a line of research has emerged trying to identify tools and contexts to develop teacher noticing (Fernández \& Choy, 2020).

\section{a. Professional noticing}

A professional vision is the ability to see certain phenomena in a particular way which distinguishes a professional or expert in a certain area from someone who is not (Goodwin, 1994). In the case of mathematics teaching, a professional vision (or professional noticing) allows teachers to identify relevant aspects in a teaching-learning situation that nonprofessional people would not be able to identify (Roller, 2016) and reason about the situation using mathematical knowledge and knowledge of the teaching and learning of mathematics. Sherin (2007) characterised this competence as two sub-processes: selective attention (noticing) and knowledge-based reasoning. Selective attention is linked to the teachers' ability to focus their attention on a particular classroom situation relevant to students' learning. Knowledge-based reasoning is linked to the teachers' ability to use their available knowledge to make sense of this classroom situation. Therefore, this competence helps teachers connect theoretical knowledge with practice
(Brown, Fernández, Helliwell, \& Llinares 2020; Seidel, Stürmer, Prenzel, Jahn, \& Schäfer, 2017).

Jacobs, Lamb, and Philipp (2010) particularised professional noticing of children's mathematical thinking as a set of three interrelated skills: attending to children's strategies, interpreting children's understanding, and deciding how to respond on the basis of children's understanding. This competence is understood as a knowledge-based reasoning since teachers must attend to a classroom situation and then interpret the situation, considering their available knowledge (Sherin, 2007) to decide what to do next. Therefore, this competence highlights the need of specialised knowledge (Thomas, Jong, Fisher, \& Schack, 2017).

Professional noticing of children's mathematical thinking implies the teachers' ability to use their knowledge (mathematical content knowledge and pedagogical content knowledge) to attend to, interpret and decide what to do next (Fernández \& Choy, 2020; Thomas et al., 2017). When pre-service teachers notice children's mathematical thinking (attending to, interpreting and deciding), they have to use their knowledge (subject matter knowledge and pedagogical content knowledge).

\section{b. Professional noticing as a knowledge-based reasoning competence}

Brown et al., (2020) linked the different domains of the Mathematical Knowledge for Teaching framework 
(MKT; Ball, Thames, \& Phelps, 2008) with the three skills of noticing; attending to children's strategies implies that teachers identify important mathematical details in students' common or uncommon procedures and the roots of their mistakes (Specialized Content Knowledge, SCK). To interpret students' understanding, teachers must coordinate what has been attended with what is known about children's mathematical understanding. Therefore, in interpreting, knowledge for explaining procedures, understanding common and uncommon strategies and explaining the origin of their errors (SCK) is required. Furthermore, knowledge about which aspects of the concept are the easiest or the most difficult ones for students, which are the most common errors related to a concept and how a mathematical concept develops over time (Knowledge of Content and Students, KCS and Horizon Content Knowledge, $\mathrm{HCK}$ ) is also needed to interpret different levels of understanding. Finally, deciding how to respond involves taking into account which aspects of the concept are the easiest or the most difficult ones for students; which are the most common errors related to the concept and how a concept develops over time (KCS); and which are the strategies or representations more adequate for introducing the concept (Knowledge of Content and Teaching, KCT). Furthermore, teachers should use their knowledge about the best sources and materials to help students progress in their understanding (Knowledge of Content and Curriculum, KCC).

\section{c. Developing teacher noticing}

In recent years, an important line of research has emerged examining contexts and tools for pre-service teachers noticing development in teacher training programs (Fernández \& Choy, 2020; Shack et al., 2017). These studies have shown that using representations of practice, such as videos of classroom interactions or transcriptions of students' written responses, is a favourable context for its development (Ivars, Fernández, \& Llinares, 2020; Ivars, Fernández, Llinares, \& Choy, 2018; Sánchez-Matamoros, Fernández \& Llinares, 2015; 2019; Schack et al., 2013; van Es \& Sherin, 2008). Other contexts that can also support its development are writing narratives during their period of practice at schools (Fernández, Llinares, \& Rojas, 2020; Ivars \& Fernández, 2018), online discussions and tutor feedback (Fernández, Llinares, \& Valls 2012; Ivars \& Fernández, 2018; Llinares \& Valls, 2010). Results from these studies have shown that this competence can be developed in teacher training programmes although its development is not an easy task without a frame that guides pre-service teachers noticing (Fernández \& Choy, 2020), such as the students' learning trajectories ( Sztajn \& Wilson, 2019). 


\section{d. Hypothetical Learning}

\section{Trajectories}

Learning trajectories have been conceptualised from different perspectives (Lobato \& Walters, 2017). Nevertheless, a shared assumption is that a learning trajectory articulates the students' conceptual progress from informal thinking to a more sophisticated mathematical reasoning. Following Simon (1995), a Hypothetical learning trajectory (HLT) is made up of three components: a learning goal, learning activities, and a hypothetical learning process (levels of understanding).

Previous research has shown that students learning trajectories could provide pre-service teachers with a structured framework to focus their attention on students' thinking (Edgington, 2014; Edgington, Wilson, Sztajn, \& Webb, 2016), since they can support pre-service teachers in identifying learning goals in the instructional activities, in interpreting students' mathematical thinking and in responding with appropriate instruction ( Ivars et al., 2018; Sztajn, Confrey, Wilson, \& Edgington, 2012). Furthermore, learning trajectories can provide pre-service teachers with a mathematical language to describe students' thinking (Edgington et al., 2016).

\section{e. Using vignettes in teacher training programs}

To connect theoretical knowledge with mathematics teaching practice in teacher training programs, researchers design learning environments to provide pre-service teachers with opportunities to learn about and for practice. (Fernández Sánchez-Matamoros, Valls, \& Callejo 2018). In our research group (GIDIMAT$U A)$, these learning environments are designed using vignettes. A vignette includes a representation of practice, some questions to guide its analysis and information from previous research on students' mathematical understanding of the mathematics concept. This information can be provided as a student's hypothetical learning trajectory. This information provides pre-service teachers with the theoretical knowledge required to analyse the representation of practice.

Representations of practice are understood as depicting a classroom situation (e.g. a transcription of students' answers to an activity, or a cartoon showing an interaction teacher-student) to promote pre-service teachers' reflection and discussion of real-life contexts. A representation of practice can represent one aspect or several aspects of a class situation, but not all the characteristics of a class (Buchbinder \& Kuntze, 2018). This reduction of information makes the vignettes useful instruments in the professional development of teachers in multiple ways (Skilling \& Stylianides, 2019) since they allow teachers to focus the attention on those aspects of the practice object of learning. Furthermore, they can be designed in different formats (Friesen \& Kuntze, 2018): video recordings of real classroom situations (van Es \& Sherin, 
2008), student responses to different problems or dialogues between the teacher and the students solving various problems (Fernández et al., 2018; Ivars et al., 2020) or animations or cartoons (Herbst \& Kosko, 2014).

Research has shown that vignettes provide teachers with real contexts to analyse and interpret aspects of the teaching and learning of mathematics and provide them with opportunities to relate theoretical ideas about the teaching and learning of mathematics with examples from practice (Buchbinder \& Kuntze, 2018; Fernández et al., 2018).

Results from our research group have shown that these learning environments using vignettes support pre-service teachers' attention on important aspects of students' understanding, and therefore help them develop the competence of noticing (Buforn, Llinares, Fernández, Coles \& Brown, 2020; Fernández et al., 2012; Fernández, Sánchez-Matamoros, Moreno, \& Callejo, 2018; Ivars et al.,
2018; Ivars et al. 2020; SánchezMatamoros et al., 2019). Following, we will present an example of a learning environment related to the part-whole meaning of fraction, which is part of a pre-service primary school teachers' training programme.

\section{f. A part-whole meaning of fraction learning environment}

This learning environment is organised around six sessions lasting two hours each (Figure 1, Ivars, 2018). In the first two sessions, we introduced the mathematical elements related to the part-whole meaning of fraction to preservice teachers. They had to solve some fraction activities and analysed videoclips of students solving fraction activities. In the last four sessions, we introduced the learning trajectory of the part-whole meaning of the fraction concept. Pre-service teachers had to analyse three vignettes, using the theoretical information provided in a HLT.

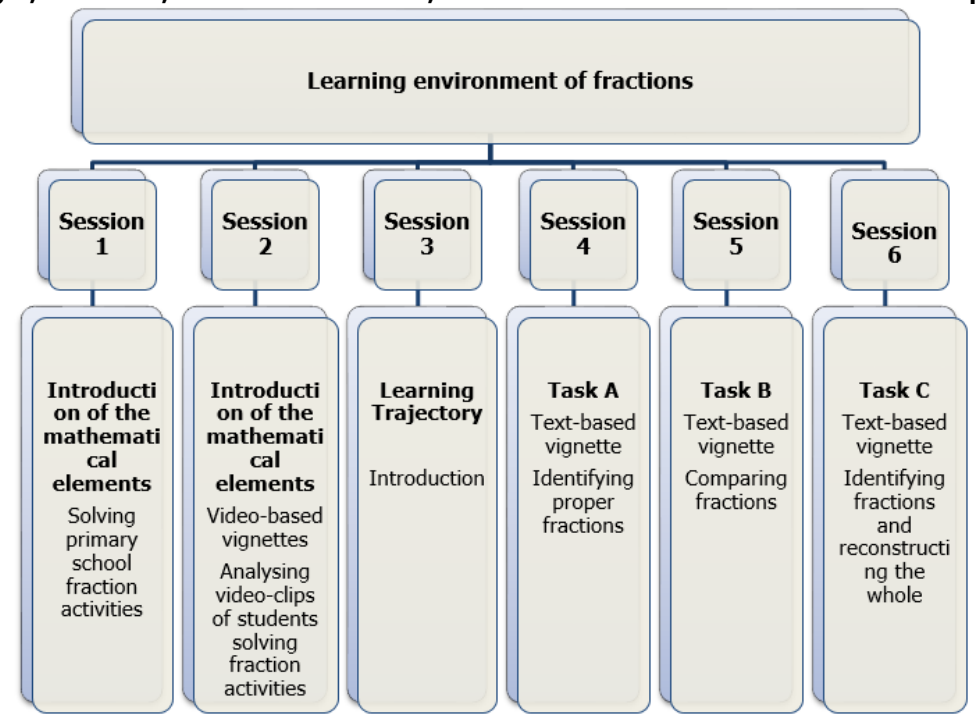

Figure 1. Learning environment of the part-whole meaning of fraction 
The HLT is provided as a theoretical document and includes: a primary school students' hypothetical learning process (levels of understanding, Figure 2), examples of primary school students' answers reflecting characteristics of each of the levels of understanding (Figure 3) and examples of activities that could help students progress in their understanding of the concept of fraction as a part-whole (Figure 4). The HLT is designed by considering the previous research on how students' reasoning about fractions develops over time (Battista, 2012; Steffe \& Olive, 2010). This theoretical document provides pre-service teachers with the theoretical knowledge (about fractions and the teaching and learning of fractions) they need to identify noteworthy mathematical aspects of the representation of practice, interpret them and support their teaching decisions.

\begin{tabular}{|c|c|c|}
\hline $\begin{array}{l}\text { Level 1. Students } \\
\text { cannot identify and } \\
\text { represent fractions } \\
>\text { Not recognising } \\
\text { that the parts into } \\
\text { which the whole is } \\
\text { partitioned must } \\
\text { be of equal size } \\
>\text { Not keeping the } \\
\text { same whole when } \\
\text { comparing } \\
\text { fractions }\end{array}$ & 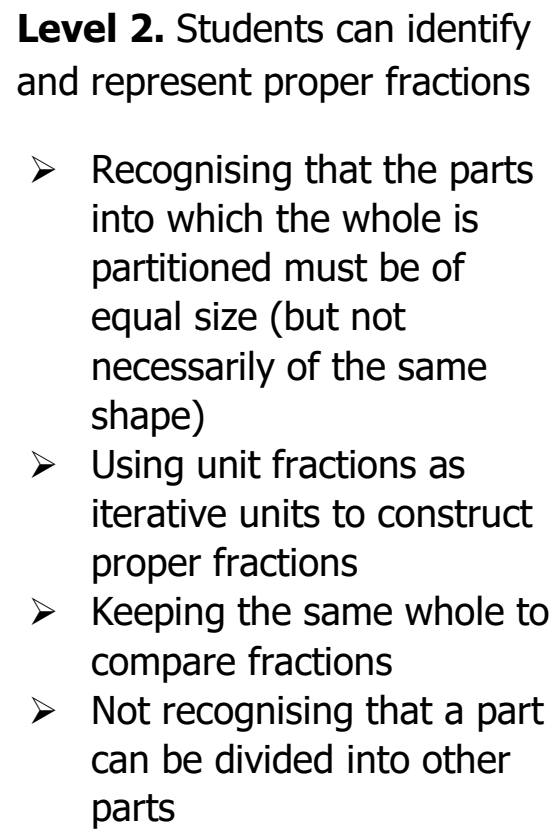 & $\begin{array}{l}\text { Level } 3 \text {. Students can } \\
\text { identify and represent } \\
\text { fractions } \\
>\text { Recognising that a part } \\
\text { can be divided into } \\
\text { other parts } \\
>\text { Using fractions as } \\
\text { iterative units to } \\
\text { construct fractions } \\
>\text { Recognising that the } \\
\text { size of a part decreases } \\
\text { when the number of } \\
\text { parts increases }\end{array}$ \\
\hline
\end{tabular}

Figure 2 . Students' hypothetical learning process

Figure 3 shows some examples of primary school students' answers included in the HLT reflecting characteristics of level 2. Student 1's answer shows difficulties in comparing fractions since he/she does not keep the same whole when comparing. Student 2's answer reflects difficulties in representing the improper fraction by not identifying the unit fraction $1 / 4$ as an iterative unit. These are characteristics of level 


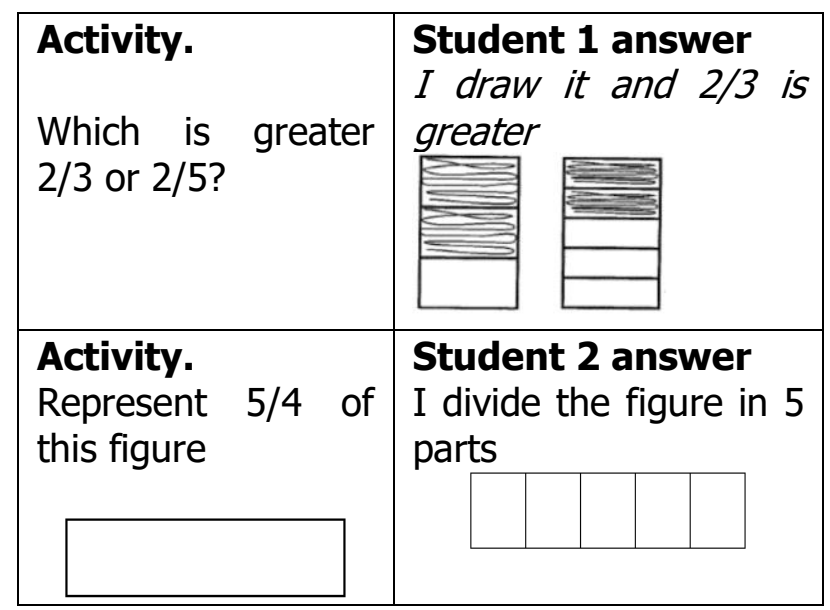

Figure 3. Examples of primary school students' answers included in the HLT

The HLT also includes examples of activities that could help primary school students progress in their understanding of the part-whole meaning of fraction. Figure 4 shows an activity that can help students progress from level 2 to level 3 of understanding according to the HLT). The activity aims at using the unit fraction as an iterative unit to construct fractions.

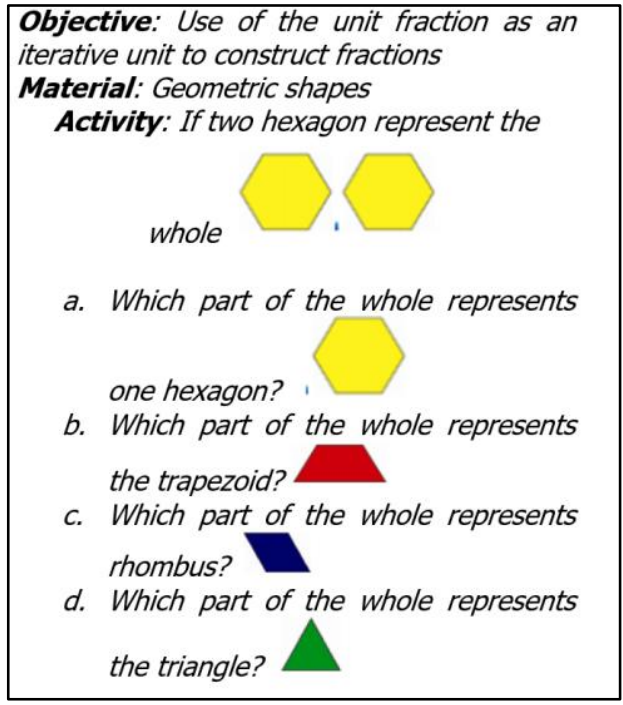

Figure 4.Examples of activities included in the HLT
The following section details the characteristics of the vignettes used in this learning environment and shows vignette 2 as an example.

\section{g. A vignette of comparing fractions}

The vignettes of the learning environment include three elements: i) transcriptions of primary school students' answers to a fraction activity showing different levels of understanding (students' names are pseudonyms), ii) guiding questions related to the three skills that articulate the competence of noticing: identifying mathematical elements, interpreting students' understanding and making teaching decisions to support students' progress in their understanding, and iii) the theoretical documents with the HTL explained before.

Vignette 2 consists of an activity of comparing fractions, the answer of three primary school students (showing different characteristics of the levels of understanding shown in the HLT), the 
HLT as a theoretical document and four guiding questions:

\section{Which is greater $4 / 5$ or $3 / 4$ ? Explain it with a picture or your words}

\section{(Answer of Ana and Iván)}

Iván: Well we think $4 / 5$ is greater than $3 / 4$

Teacher: $\quad$ And how do you know?

Ana: Because we have drawn four fifths, which is... and three quarters that is... (while she was drawing on the blackboard the following images):

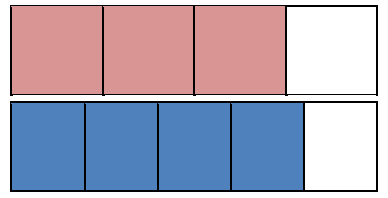

Teacher: And?

Iván: $\quad$ Well, so you can see that 4/5 is greater than $3 / 4$

Teacher: Do you all agree? ... Vicent? What do you think?

\section{(Answer of Marta and Vicent)}

Vicent: Well, we agree, but we've done it differently.

Teacher: Could you show us how have you done it?

Marta: Yes, look, here we have 4/5 that represents four out of five (while she was drawing the following figure):

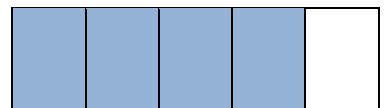

And, then we have 3/4 which also represents three out of four that is... (She draws the following figure):

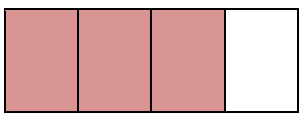

Teacher: What do you think? Has anyone done it in another way? No one? Can someone else explain, differently, that $4 / 5$ is greater than $3 / 4$ ?

\section{(Answer of Núria and Louis)}

Louis: Yes, of course ... we can but... we have not drawn it

Teacher: What have you done?

Núria: Well we thought that 4/5 needs $1 / 5$ to complete the whole and $3 / 4$ needs $1 / 4$ to complete it. Therefore... as $1 / 5$ is smaller than $1 / 4$, then $4 / 5$ is greater than $3 / 4$ because it needs less to complete the whole than $3 / 4$.

Louis: That's it!

\section{h. Guiding questions}

- Q1- Describe the activity considering the learning objective: what are the mathematical elements that the student needs to solve it?

- Q2- Describe how each pair of students has solved the activity identifying how they have used the mathematical elements involved and the difficulties they have had with them. 
- Q3- What are the characteristics of students' understanding (levels of understanding of the Hypothetical Learning Trajectory) that can be inferred from their responses? Justify your answer.

- Q4- How could you respond to these students? Propose a learning objective and a new activity to help students progress in their understanding of fractions.

The mathematical elements that should be considered to solve this activity of comparing proper fraction are the wholes must be the same to compare and the inverse relationship between the number of the parts and the size of each part (a bigger number of parts makes smaller parts). The answer of Ana and Iván show characteristics of level 2 since they identify that the wholes must be the same to compare fractions (they represent both fractions using the same whole). Nevertheless, their answer does not show characteristics of understanding the inverse relationship between the number of the parts and the size of each part (since their answer relies on the graphical representation). The second couple, Marta and Vicent, shows characteristics of the level 1 since they do not keep the same whole to compare both fractions nor show understanding of the inverse relationship. This couple provides a correct answer but using an incorrect reasoning. Finally, Núria and Louis answer focuses on the inverse relationship between the number of the parts and the size of each part as they stated that "[...] $4 / 5$ needs $1 / 5$ to complete the whole and $3 / 4$ needs $1 / 4$ to complete it". Therefore they show characteristics of level 3.

\section{METHODOLOGY \\ a. Participants}

In this learning environment participated 85 pre-service primary school teachers (PTs) enrolled in a university course related to the teaching and learning of mathematics during their third out of the four years of the degree to become a primary school teacher.

\section{b. Instrument and data collection}

During the learning environment PTs solved the three vignettes individually. Data of this research were PTs' written answers to questions Q2, Q3 and, Q4 to the three vignettes. To maintain participants' anonymity we named PTs as: PT1, PT2 .... PT85.

\section{c. Analysis}

We made a qualitative analysis of PTs' answers to the three vignettes in two phases. In the first phase, three researchers analysed PTs' answers, individually, according to whether they (i) identified the mathematical elements in the student's answers; (ii) interpreted the student's understanding considering the HLT and the mathematical elements 
identified; and (iii) provided activities that helped students progress in their understanding. We then compared our results and discussed our discrepancies (triangulation process) until we reached an agreement. From the analysis of (i) and (ii), we identified three categories (groups of PTs) regarding the details identified and how they interpreted students' understanding:

- Non-evidencers. PTs who interpreted students' understanding but did not provide details from students' answers to support their interpretations.

- Adders. PTs who interpreted students' understanding providing details from students' answers, but they added information that cannot be inferred from students' answers.

- Evidencers. PTs who interpreted students' understanding providing details from students' answers to support their interpretations.

Then, we analysed whether each group of PTs provided activities focused on students' conceptual progression. In the second phase, we analysed changes in PTs' answers along the three vignettes. These changes provided us with information to characterise PTs noticing enhancement.

\section{RESULTS}

\section{a. Interpreting and deciding relationship}

Our results highlight that those PTs who provided a more detailed discourse to support their interpretations
(Evidencers) were more able to provide activities to support students' conceptual progression in the three vignettes. We are going to show this relationship in the vignette of comparing fractions as an instance of this result.

In the task of comparing fractions, 71 out of the 85 PTs interpreted students' understanding, while 14 did not interpret it since they only provided descriptive answers. Fifty-four out of the 71 PTs who interpreted students' understanding provided details from students' answers to support their interpretations (Evidencers) and 17 out of the 71 PTs did not provide details to support their interpretations (Nonevidencers).

For instance, PT23 interpreted students' understanding as follows (emphasis added to the mathematical elements identified):

Ana and Ivan $\rightarrow$ They are at level 2 since when they compare fractions, they recognise that the wholes must be the same.

Marta and Vicent $\rightarrow$ They are at level 1 since they do not keep the same whole when they compare fractions

Louis and Núria $\rightarrow$ They are at level 3 since when comparing fractions they recognise that the wholes must be the same and establish the inverse relationship between the number of the parts and the size of each part.

This PT identified the mathematical elements in students' answers, (e.g. "when they compare fractions recognise that the wholes must be the same" or "They establish the inverse relationship between the number of the parts and 
the size of each part') and interpreted students' mathematical thinking recognising the relationship between those mathematical elements and the different levels of the HLT. Nevertheless, he did not provide details from students' answers to support their interpretations (Non-evidencer).

On the other hand, PT73 interpreted students' understanding as follows (emphasis added to the mathematical elements identified):

Ana and Ivan $\rightarrow$ They are at level 2 since they keep the same whole when they represent both fractions. Then they compare both areas to provide the answer.

Marta and Vicent $\rightarrow$ They are at level 1 . When they represent both fractions, they only notice four shaded parts in $4 / 5$ and three shaded parts in $3 / 4$. Therefore, although they provide a correct answer the reasoning is not correct because they do not keep the same whole when comparing fractions.

\section{Louis and Núria $\rightarrow$ Level 3}

These students use the mathematical element inverse relationship between the number of the parts and the size of each part, to justify their answer since they stated "...4/5 is greater than $3 / 4$ because it needs less to complete the whole than 3/4needs".

PT73 identified the mathematical elements in students' answers and interpreted students' mathematical thinking recognising the relationship between those mathematical elements and the different levels of HLT. Moreover, she provided details from students' answers to support her interpretations. For instance when she wrote that Marta and Vicent do not keep the same whole when comparing fractions and they "[...] only notice four shaded parts in $4 / 5$ and three shaded parts in $3 / 4$. Therefore, although they provide a correct answer the reasoning is not correct $[\ldots] "$. She also interpreted students' understanding of the inverse relationship providing details from students' answer when she stated that Louis and Nuria use this mathematical element to "justify their answer since they stated "...4/5 is greater than $3 / 4$ because it needs less to complete the whole than $3 / 4$ needs".

Excerpts from the answers, such as the ones from PT73 (Evidencer) and PT23 (Non-evidencer) show the different ways in which PTs interpreted students understanding in this task.

Regarding the activities provided, 26 out of the 54 PTs, who interpreted students' thinking providing details (Evidencers), proposed at least one activity to help students progress in their understanding of fractions (48\%). On the other hand, five of the 17 PTs who did not provide details in their interpretations (Nonevidencers), proposed at least one activity (29\%).

In this context, the Non-evidencer PTs provided activities that were not related to the objective proposed or without sense. For instance, with the objective of understanding that the wholes must be the same to compare fractions, PT23 provided an activity of representing fractions and partitioning the whole that was not related with the objective proposed: 
Objective: Recognise that the whole must be the same when comparing fractions.

Activity: We have two equal paper sheets and we want to divide one of them in $1 / 4$ and the other in $1 / 2$.

On the other hand, PTs in the Evidencer group provided activities connected with the learning objective that could help students progress in their understanding. For instance, PT73 provided the following activity, focused on comparing unitary fractions, to help Ana and Iván understand the inverse relationship between the number of parts and its size. This activity provides students various unitary fractions of the same whole. Hence, it requires PTs comparing the number of the parts of the denominator and realising that a bigger number of parts in the denominator makes each part smaller:

Objective: To understand the inverse relationship between the number of the parts and the size of each parts; a bigger number of parts makes smaller parts.

Activity: Jose, Rosa and Carlos buy the same cake. Jose eats $1 / 3$ of his cake,
Rosa eats $1 / 4$ of her cake and Carlos eats $1 / 5$ of his cake. Who do eat more cake? Explain it.

In the next section, we present how these different ways of interpreting changed through the learning environment.

\section{b. Noticing enhancement}

Through the three vignettes (Table 1), 42 PTs consistently provided a detailed discourse (Evidencers), and 10 PTs provided a non-detailed discourse (Non-evidencers). Twenty-eight PTs improved their discourse since they shifted from Non-evidencers or Adders to Evidencers. This discourse' improvement was followed by an improvement of PTs' ability to provide activities according to students' understanding (from $34 \%$ in the first vignette to $63 \%$ in the last, see Table 2). However, five PTs, showed a regression since they changed from Evidencers or Adders to Non-evidencers.

Table 1. Pre-service teachers discourse progress in the learning environment

\begin{tabular}{lccccc} 
& \multicolumn{5}{c}{ Discourse progress } \\
\cline { 2 - 6 } $\begin{array}{l}\text { Ways of interpreting } \\
\text { students' } \\
\text { thinking }\end{array}$ & $\begin{array}{c}\text { From Non- } \\
\text { evidencer } \\
\text { or Adder to } \\
\text { Evidencer }\end{array}$ & $\begin{array}{c}\text { Consistently } \\
\text { Non-evidencer }\end{array}$ & $\begin{array}{c}\text { From } \\
\text { Evidencer or } \\
\text { Adder to Non- } \\
\text { evidencer }\end{array}$ & $\begin{array}{c}\text { Consistently } \\
\text { Evidencer }\end{array}$ & TOTAL \\
\hline $\begin{array}{l}\text { Interpreting through the } \\
\text { three tasks }\end{array}$ & 12 & 1 & 2 & 19 & 34 \\
$\begin{array}{l}\text { Difficulties in at least } \\
\text { one task }\end{array}$ & 16 & 9 & 3 & 23 & 51 \\
\hline Total & 28 & 10 & 5 & 42 \\
\hline
\end{tabular}


Table 2. Number of activities provided in each task considering the discourse provided

\begin{tabular}{lcccc}
\hline & $\begin{array}{c}\text { Number of } \\
\text { activities } \\
\text { in Task 1 }\end{array}$ & $\begin{array}{c}\text { Number of } \\
\text { activities in } \\
\text { Task 2 }\end{array}$ & $\begin{array}{c}\text { Number of } \\
\text { activities in } \\
\text { Task 3 }\end{array}$ \\
\hline From Nonevidencer/Adder to Evidencer & $(28)$ & $19(34 \%)$ & $14(25 \%)$ & $35(63 \%)$ \\
Always Non-evidencer & $(10)$ & $4(20 \%)$ & $2(10 \%)$ & $9(45 \%)$ \\
From Evidencer/Adder to Nonevidencer & $(5)$ & $4(40 \%)$ & $2(20 \%)$ & $2(20 \%)$ \\
Always Evidencer & $(42)$ & $45(54 \%)$ & $21(25 \%)$ & $49(58 \%)$ \\
\hline
\end{tabular}

\section{DISCUSSION AND CONCLUSION}

Our results allowed us to characterise the enhancement of teacher noticing through PTs changes in the discourse generated, since the progress in the discourse, considering the details used to support their interpretations, influenced PTs ability to propose activities.

These results suggest a relationship between the discourse provided by PTs interpretations of students' mathematical understanding and the activities provided; PTs who produced a more mathematical detailed discourse to interpret students' understanding proposed more activities according to students' understanding. Therefore, the value of a detailed mathematical discourse can be seen "as a major learning outcome in its own right" (Clarke, 2013, p. 22). In this sense, "the more sensitive you are to noticing details, the more tempted you are likely to be to act responsively" (Mason, 2002, p. 248). Consequently, it seems that producing a detailed discourse may be distinctive in enhancing noticing. Our results seem to suggest that a detailedsensitive discourse leads PTs to a more attentive focus on students' understanding and prepares them to make instructional decisions based on students' mathematical understanding.

The regression of some PTs can be explained by the difficulties interpreting some of the mathematical elements of the fraction concept in the vignettes. This highlights the critical role played by mathematical content knowledge in the enhancement of teacher noticing.

Furthermore, our results show that the characteristics of the vignettes used and the HLT supported PTs to link theoretical knowledge and practice, and helped them improve their professional discourse. This improvement can be seen as evidence of PTs noticing enhancement since PTs who generated a more detailed discourse to interpret students' understanding, were more able to provide an activity to support students' conceptual progression. Nevertheless, the enhancement of noticing is challenging and remains dependent on PTs' mathematical content knowledge, since the mathematical elements linked to each vignette generated different difficulties in PTs. 
We are aware that we cannot generalise our results, and more research is necessary to analyse how PTs' noticing develops during teacher training programs. In future projects, it will be interesting to analyse how PTs use the knowledge learned during the university courses in their internship period at the schools to notice children's mathematical thinking.

\section{ACKNOWLEDGEMENTS}

The project I+D+i EDU2017-87411-R from Ministry of Economy and Competitiveness (MINECO, Spain) supported this research.

\section{REFERENCES}

Ball, D. L., Thames, M. H., \& Phelps, G. (2008). Content knowledge for teaching what makes it special? Journal of Teacher Education, 59(5), 389-407. https://doi.org/10.1177/00224871 08324554

Battista, M. T. (2012). Cognition-based assessment \& teaching of fractions: Building on students' reasoning. Portsmouth: Heinemann.

Brown, L., Fernández, C., Helliwell, T., \& Llinares, S. (2020). Prospective mathematics teachers as learners in university and school contexts. From university-based activities to classroom practice. In G. M. Lloyd \& O. Chapman (Eds) International Handbook of Mathematics
Teachers Education: Volume 3. Participants in Mathematics Teacher Education (vol. 13, pp. 343-366). Koninklijke Brill NV, Leiden.

https://doi.org/10.1163/97890044 19230014

Buchbinder, O, \& Kuntze, S. (2018). Representations of practice in teacher education and research Spotlights on Different Approaches. In O. Buchbinder \& S. Kuntze (Eds.), Mathematics teachers engaging with representations of practice. $A$ dynamically evolving field (pp. 18). Cham, Switzerland: Springer. https://doi.org/10.1007/978-3319-70594-1 1

Buforn, A., Llinares, S., Fernández, C., Coles, A., \& Brown, L. (2020). Pre-service teachers' knowledge of the unitizing process in recognizing students' reasoning to propose teaching decisions. International Journal of Mathematical Education in Science and Technology. https://doi.org/10.1080/0020739 $\underline{\mathrm{X} .2020 .1777333}$

Clarke, D. J. (2013). Contingent conceptions of accomplished practice: the cultural specificity of discourse in and about the mathematics classroom. ZDM Mathematics Education, 45(1), 21-33. https://doi.org/10.1007/s11858012-0452-8 
Edgington, C. (2014). Teachers' uses of a learning trajectory as a tool for mathematics lesson planning. In J. J. Lo, K. R. Leatham \& L. R. Van Zoest (Eds.), Research trends in mathematics teacher education (pp. 261-284). Cham: Springer. https://doi.org/10.1007/978-3319-02562-9 14

Edgington, C., Wilson, P.H., Sztajn, P., \& Webb, J. (2016). Translating learning trajectories into useable tools for teachers. Mathematics Teacher Educator, 5(1), 65-80. https://doi.org/10.5951/mathteac educ.5.1.0065

Fernández, C., \& Choy, B. H. (2020). Theoretical lenses to develop mathematics teacher noticing. Learning, Teaching, Psychological, and social perspectives. In S. Llinares \& $\mathrm{O}$. Chapman (Eds) International Handbook of Mathematics Teachers Education: Volume 2. Tools and Processes in Mathematics Teacher Education (vol. 12, pp. 337-360). Koninklijke Brill NV, Leiden. https://doi.org/10.1163/97890044 $\underline{18967013}$

Fernández, C., Llinares, S, \& Rojas, Y. (2020). Prospective mathematics teachers' development of noticing in an online teacher education program. ZDM Mathematics Education.

https://doi.org/10.1007/s11858020-01149-7
Fernández, C., Llinares, S., \& Valls, J. (2012). Learning to notice students' mathematical thinking through on-line discussions. ZDM. Mathematics Education, 44, 747759.

https://doi.org/10.1007/s11858012-0425-y

Fernández, C., Sánchez-Matamoros, G., Valls, J., \& Callejo, M. L. (2018). Noticing students' mathematical thinking: characterization, development and contexts. AIEM. Avances en Investigación Matemática, 13, 39-61. https://doi.org/10.35763/aiem.v0i 13.229

Fernández, C., Sánchez-Matamoros, G., Moreno, M., \& Callejo, M. L. (2018). La coordinación de las aproximaciones en la comprensión del concepto de límite cuando los estudiantes para profesor anticipan respuestas de estudiantes [Coordination of approximations in the understanding of the limit concept when prospective teachers anticipate students' answers]. Enseñanza de las Ciencias, 36(1), 143-

162. https://doi.org/10.5565/rev/ ensciencias. 2291

Friesen, M., \& Kuntze, S. (2018). Competence assessment with representations of practice in text, comic and video format. In O. Buchbinder \& S. Kuntze (Eds.), Mathematics teachers engaging 
with representations of practice. A dynamically evolving field (pp. 113-130). Cham, Switzerland: Springer.

https://doi.org/10.1007/978-3319-70594-1 7

Goodwin, C. (1994). Professional vision. American Anthropologist, 96, 606-633. https://doi.org/10.1525/aa.1994. $\underline{96.3 .02 \mathrm{a} 00100}$

Herbst, P., \& Kosko, K.W. (2014). Using representations of practice to elicit mathematics teachers' tacit knowledge of practice: a comparison of responses to animations and videos. Journal of Mathematics Teacher Education, 176) 515-537. https://doi.org/10.1007/s10857013-9267-y

Ivars, P. (2018). Mirar profesionalmente el pensamiento matemático de los estudiantes: $\quad$ El esquema fraccionario [Professional Noticing of students mathematical thinking: the fractional schema] (unpublished Doctoral dissertation). University of Alicante, Spain.

Ivars, P., \& Fernández, C. (2018). The role of writing narratives in developing pre-service primary teachers noticing. In G. Stylianides \& K. Hino (Eds.), Research advances in the mathematical education of preservice elementary teachers. An international perspective (pp. 245-260). Cham: Springer. https://doi.org/10.1007/978-3319-68342-3 17

Ivars, P., Fernández, C., \& Llinares, S. (2018). Características del desarrollo de la competencia mirar profesionalmente el pensamiento de los estudiantes sobre fracciones [Characteristics of the development of noticing students' mathematical thinking related to fraction]. In L. J. Rodríguez-Muñiz, L. MuñizRodríguez, A. Aguilar-González, P. Alonso, F. J. García García, \& A. Bruno (Eds.), Investigación en Educación Matemática XXII (pp. 270-279). Gijón: SEIEM.

Ivars, P., Fernández, C., \& Llinares, S. (2020). A Learning Trajectory as a scaffold for pre-service teachers' noticing of students' mathematical understanding. International Journal of Science and Mathematics Education, 18, 529-548.

https://doi.org/10.1007/s10763019-09973-4

Ivars, P., Fernández, C., Llinares, S., \& Choy, B. H. (2018). Enhancing noticing: Using a hypothetical learning trajectory to improve pre-service primary teachers' professional discourse. Eurasia. Journal of Mathematics, Science and Technology Education, 14(11), em1599. 


\section{https://doi.org/10.29333/ejmste/ 93421}

Jacobs, V. R., Lamb, L. L., \& Philipp, R. A. (2010). Professional noticing of children's mathematical thinking. Journal for Research in Mathematics Education, 41(2), 169-202.

\section{https://doi.org/10.5951/jresemat heduc.41.2.0169}

Llinares, S., \& Valls, J. (2010). Prospective primary mathematics teachers' learning from on-line discussions in a virtual videobased environment. Journal of Mathematics Teacher Education, 13, 177-196. https://doi.org/10.1007/s10857009-9133-0

Lobato, J., \& Walters, C. D. (2017). A taxonomy of approaches to learning trajectories and progressions. In J. Cai (Ed.), Compendium for research in mathematics education (pp.74101). Reston, VA: National Council of Teachers of Mathematics.

Mason, J. (2002). Researching your own practice. The discipline of noticing. London: RoutledgeFalmer. https://doi.org/10.4324/97802034 71876

Mason, J. (2020). Learning about noticing, by, and through, noticing. ZDM, Mathematics Education.

\section{.https://doi.org/10.1007/s11858-} $\underline{020-01192-4}$

National Council of Teachers of Mathematics. (2014). Principles to actions: Ensuring mathematics success for all. Reston, VA: NCTM.

Roller, S. A. (2016). What they notice in video: A study of prospective secondary mathematics teachers learning to teach. Journal of Mathematics Teacher Education, 19(5), 477-498. https://doi.org/10.1007/s10857015-9307-x

Sánchez-Matamoros, G., Fernández, C., \& Llinares, S. (2015). Developing pre-service teachers' noticing of students' understanding of the derivative concept. International Journal of Science and Mathematics Education, 13(6), 1305-1329. https://doi.org/10.1007/s10763014-9544-y

Sánchez-Matamoros, G., Fernández, C., \& Llinares, S. (2019). Relationships among prospective secondary mathematics teachers' skills of attending, interpreting and responding to students' understanding. Educational Studies in Mathematics, 100(1), 83-99.

https://doi.org/10.1007/s10649018-9855-y

Schack, E. O., Fisher, M. H., \& Wilhelm, J. A. (Eds.). (2017). Teacher 
noticing: Bridging and broadening perspectives, contexts, and frameworks. Cham, Switzerland: Springer.

https://doi.org/10.1007/978-3319-46753-5

Seidel, T., Stürmer, K., Prenzel, M., Jahn, G., \& Schäfer, S. (2017). Investigating pre-service teachers' professional vision within university-based teacher education. In D. Leutner, J. Fleischer, J. Grünkorn, \& E. Klieme (Eds.),Competence Assessment in Education (pp. 93109). Cham, Switzerland: Springer. https://doi.org/10.1007/978-3319-50030-0 7

Sherin, M. G. (2007). The development of teachers' professional vision in video clubs. In R. Goldman, R. Pea, B. Barron, \& S. J. Denny (Eds.), Video research in the learning sciences, 383-395.

Simon, M. A. (1995). Reconstructing mathematics pedagogy from a constructivist perspective. Journal for Research in Mathematics Education, 114-145. https://doi.org/10.5951/jresemat heduc. 26.2.0114

Skilling, K., \& Stylianides, G. (2019). Using vignettes in educational research: a framework for vignette construction. International Journal of Research and Method in Education, 541556. https://doi.org/10.1080/1743727 X.2019.1704243

Steffe, L. P., \& Olive, J. (2010). Children's fractional knowledge. Springer Science \& Business Media. https://doi.org/10.1007/978-14419-0591-8

Sztajn, P., Confrey, J., Wilson, P.H., \& Edgington, C. (2012). Learning trajectory based instruction: Toward a theory of teaching. Educational Researcher, 41(5), 147-156. https://doi.org/10.3102/0013189 X12442801

Sztajn, P., \& Wilson, P. H. (2019). Learning trajectories for teachers: Designing effective professional development for math instruction. Nueva York, NY: Teachers' College Press.

Thomas, J., Jong, C., Fisher, M. H., \& Schack, E. O. (2017). Noticing and knowledge. Exploring Theoretical connections between professional noticing and mathematical knowledge for teaching. The Mathematics Educator, 26(2), 3-25.

van Es, E. A., \& Sherin, M. G. (2002). Learning to notice: Scaffolding new teachers' interpretations of classroom interactions. Journal of Technology and Teacher Education, 10(4), 571-595.

van Es, E. A., \& Sherin, M. G. (2008). Mathematics teachers' "learning 
to notice" in the context of a video club. Teaching and Teacher Education, 24(2), 244-276.

\section{$\underline{6.11 .005}$}

